the Irish Wheelchair Association, has been formed now for some years with the aim of helping in social activities, sport and problems such as provision of transport for paraplegics. We have much to be thankful for to Stoke Mandeville, and in particular to Sir Ludwig Guttmann and Dr. Walsh, in the progress that we have made to date.

I am of the opinion that our planning has been correct and the right place to put a spinal injuries unit is in the main medical rehabilitation centre within the orbit of the main general and teaching hospital group.

\title{
ORGANISATION AND FUNCTION OF THE FRENCH SWISS PARAPLEGIC CENTRE
}

\author{
By Alain B. Rossier, M.D. \\ From the Paraplegic Centre of the University Institute for Physical Medicine \\ and Rehabilitation, Beau-Séjour Hospital, Geneva, Switzerland
}

\section{INTRODUCTION}

BEFORE starting our description, it seemed necessary to us to give a short historical notice about the basic facts which led to the construction of our centre.

About Io years ago, serious consideration was given to the possibility of building a paraplegic centre in Switzerland as it was increasingly realised how much such an institution was needed. At that time spinal cord patients were taken care of for the most part in neurosurgical and orthopaedic hospitals which were neither equipped and fitted for the treatment of such patients nor trained in the necessary team-work. In 1956 a committee was founded to study this problem, thanks to the voluntary participation of paraplegics, doctors, lawyers, hospital directors, representatives of insurance companies, the Government, Army and paramedical personnel. Finally it was decided to build this centre in Basle, a German-speaking canton, close to the French and German borders. Federal and private funds as well as contributions from each canton were expected to finance the centre. However, as this project was encountering difficulties in its realisation and was progressing slowly, Geneva canton, which was reorganising the Department of Physical Medicine and Rehabilitation of its University Hospital decided in 1963 to build its own paraplegic centre which was opened two years later in November I965. As a next important step, with the agreement of the Federal Organisation on Social Insurance it was decided by medical and political authorities in Geneva canton not to restrict this centre only to the inhabitants of this canton, but also to open it to patients from other Frenchspeaking regions. It is scheduled in the near future to increase the present 20 beds capacity of the centre to 40 beds in order to be able to cope with the demand of the other French-speaking cantons. The Centre in Basle, which has been opened in June 1967, will take care of patients from German-speaking regions. From a medical, psychological and demographic point of view, such a solution with two Centres seems to be favourable. 


\section{DESCRIPTION OF THE CENTRE}

The Centre in Geneva is part of the University Institute for Physical Medicine and Rehabilitation and admits male and female patients at and over I 5 years of age. It is composed of three six-bed rooms (figs. IA and B), one two-bed room, four toilets, one enema room, a room with sinks and a washing-machine for patients, a bathroom with two oversized tubs with a hoister for dependent patients and another regular tub for independent patients, and lastly a shower-room within

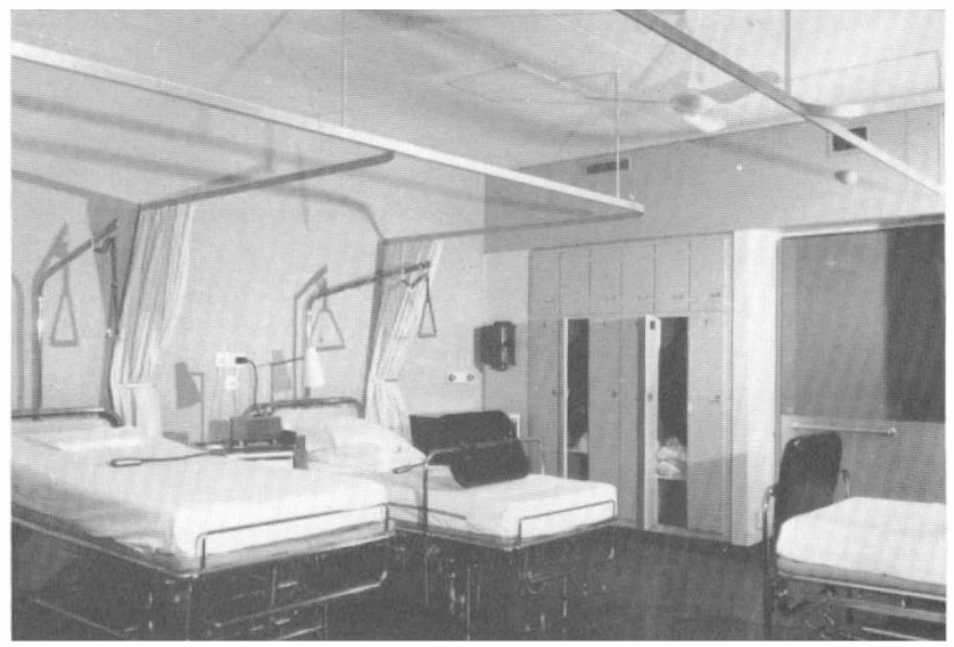

FIG. IA

Partial view of one of the six-bed rooms: electrical high-low beds, individual curtains, $\mathrm{X}$-ray plug and oxygen and vacuum in the corner of the room, fans, intercommunication system to and from the nurses' room (above the door), large overhead helpers which can also be moved to the right or to the left side at about 30 degrees from the middle of the bed as to make the access to the bed easier (quadriplegics). Note the reclinable padded board against drop foot; the whole system can be moved in length and height and is removable when not needed (e.g. patient lying on his abdomen).

easy reach for patients in a shower wheelchair. Each of the patients' rooms is equipped with ceiling fans, oxygen and vacuum, and an X-ray plug which allows $\mathrm{X}$-rays to be taken at the bedside and avoids transport of patients with acute injuries (see fig. IA). A large day-room is also used as a dining-room with tables, built for wheelchairs. Other installations are head nurses' room, nurses' room, a large tea kitchen and a storage room which is also used for the preparation of intermittent catheterisation sets and of any other urological packing.

All of these installations are housed on the third floor of Beau-Séjour Hospital, which is a 352-bed university hospital for patients who need rehabilitation treatments and who have been sent by the different medical and surgical services located in the main university I630-bed hospital which is connected to Beau-Séjour 
by means of an underground corridor. Physical medicine and rehabilitation facilities, including occupational therapy, for any patient in Beau-Séjour, i.e. also for paraplegics, are located in the first floor, as is the cystoscopy room of the Centre and the office of its resident and its chief with his secretary. Other installations on the first floor are X-ray room, laboratory, library and electrodiagnostic department with its chief, who is a neurologist and neurophysiologist; this department is also attached to the Institute.

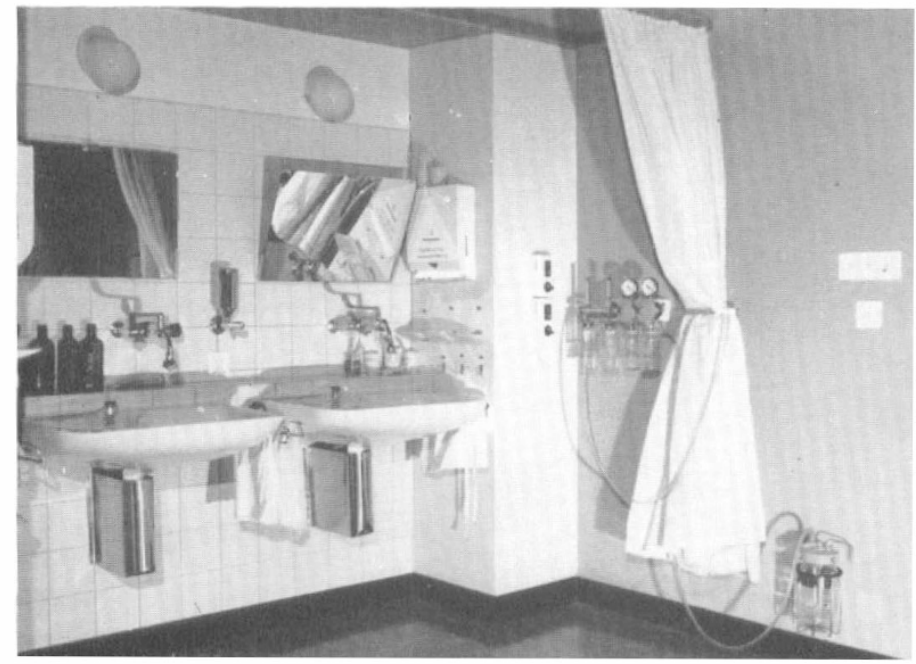

FIG. IB

Another sight of the six-bed room: washbasin, insulated drainage pipes for prevention of burning of the knee, surgical faucets for quadriplegics, thermostatic control of water temperature, inclinable mirrors. Note the paper towel and the liquid soap for nurses and the towels and pieces of soap for patients in order to decrease the danger of crossed infection. All of the electrical plugs are within easy reach for patients in wheelchairs.

\section{MEDICAL ORGANISATION OF THE CENTRE}

Any newly injured patient with spinal cord involvement is brought into the main hospital to the emergency department, where he is examined by the neurosurgeon and the chief of the spinal centre and where the necessary X-rays are taken. The first therapeutic measures are started according to the condition of the patient and any special investigative procedure which could be useful, such as air myelogram, is planned. When the patient does not present respiratory difficulties which could necessitate his temporary admission in the re-animation unit, he is transferred immediately to the paraplegic centre or this is done within two or three days when special investigative procedures or surgical measures have been necessary in the neurosurgical unit. Re-animation and neurosurgical units are equipped with the necessary material which we use for our patients, such as special turning beds, Dunlopillo packs for the prevention of pressure 
sores (Kahn and Rossier, I966) and urological sets for intermittent catheterisation. As the result of team-work with the Centre, these units have become familiar with the specific problems of spinal cord patients. When the patient is not admitted immediately to the Centre, he is visited by its chief at least twice daily.

The medical work is organised in such a way that most of the patients' problems in the centre will be taken care of by its chief and his resident. As the smooth operation of such a multi-disciplinary unit as a paraplegic centre is related to multiple specialities which cannot be expected to be mastered by a single person, consultants in various fields will be called for whenever needed. However, the final decision rests with the medical staff of the Centre who have gained experience by continuous contact with these patients. The longer consultants and staff of the Centre have been working together, the better they will know each other's problems. Whenever an operation is needed the patient is moved in his own bed to the theatre through the underground corridor and is brought back to his room immediately after the intervention.

Short rounds are made every day by the chief of the centre or his resident, and once a week a morning is reserved for the grand round where the case of each patient is reviewed with respect to medical, social and professional problems in front of the medical team of the Institute and of the Centre, nurses, social worker and representatives of physical and occupational therapy. Every Thursday afternoon is reserved for investigative urological procedures such as cystometrography, cystometry, sphincterometry or cystourethrography, with and without nerve or mucosal anaesthesia. Another afternoon is reserved for intravenous pyelograms.

Once a week the consultant in urology who is working with the spinal centre performs endoscopic examinations and minor surgical interventions as needed, and medical cases are reviewed with the consultant in medicine who is the assistant chief of the medical clinic in Beau-Séjour. A weekly P.M. and R. conference takes care of the individual prescriptions and corrections for braces, self-help devices and wheelchairs as well as of the evaluation of patients' progresses.

Twice a month, chosen groups of in-patients and out-patients are given freely the opportunity to attend a general discussion where they can expose their problems, present their own experiences to each other and ask for advice. These conferences have been shown to relieve much of patients' anxiety with regard to the problems which they will have to face when discharged home.

Twice a month administrative questions of the centre are discussed by the chief and his head nurse.

\section{PERSONNEL OF THE CENTRE}

The personnel of the centre consists of a head nurse, I I registered nurses and 8 auxiliaries (non-registered nurses and helpers). Every need of the centre is taken care of by them, including the preparation of the sets for intermittent catheterisation. There is central sterilisation in the main hospital and no sterilisation is made at the centre. Cold gas sterilisation is used for any material in plastic or in rubber as well as for cystoscopic material.

The centre has a social worker who also takes care of patients under treatment 
in the Institute. One out of the four occupational therapists and four of the 33 physiotherapists of the Institute are working with our spinal cord patients; one physiotherapist is employed full time in the unit and the most experienced physiotherapist in paraplegics' re-education heads the team, members of which are rotated regularly in order to give the opportunity to treat spinal cord patients to the other physiotherapists of the Institute who are interested in this field.

\title{
SUMMARY
}

After relating the circumstances which ended in the creation of the first Swiss University Paraplegic Centre in Geneva, a brief description of the Centre is given. Its medical organisation is described and the composition of its personnel is presented.

\section{REFERENCES}

KAHN, E. A. \& Rossier, A. B. (1966). Management of acute cervical spine injuries. Postgrad. Med. 39, 37-44.

Rossier, A. (I963). The organization and function of the Spinal Cord Injury Service of the Veterans Administration Hospital, Long Beach, California. $\mathcal{F}$. Internat. Coll. Surg. 93, 225-237.

\section{ORGANISATION OF AN AUTONOMOUS SPINAL INJURIES UNIT}

\author{
By M. Sarrias Domingo, M.D. \\ Instituto Guttmann, Barcelona, Spain
}

ThE Instituto Guttmann, legally dependent from the National Association of Civilian Cripples, is a 44-bed autonomous Spinal Unit in Barcelona, a city of about two million people in the region of Catalonia, one of the most industrial areas in Spain. The aim of the Centre is the total care of the paraplegic patient, from the acute stage to domestic, social and industrial resettlement.

\section{HISTORY}

Señor Gonzalez is the founder and President of the Board of Instituto Guttmann. His desire to set up a Paraplegic Centre in Barcelona was activated by his own disablement as the result of a motor-car accident, some nine years ago, when he became a tetraplegic.

After his accident he was examined by many leading surgeons and other specialists in Barcelona, but despite continued medical care his condition deteriorated steadily.

Señor Gonzalez was subsequently transferred to the National Spinal Injuries Centre, Stoke Mandeville Hospital in England, where he remained for I I months. It was then that he began to be concerned about the fate of those paraplegics 